\title{
Corrigendum
}

\section{Corrigendum to "Survival Analysis of Factors Influencing Cyclic Fatigue of Nickel-Titanium Endodontic Instruments"}

\author{
Eva Fišerová, ${ }^{1}$ Martina Chvosteková, ${ }^{1,2}$ Silvie Bělašková, ${ }^{1,3}$ \\ Michal Bumbálek, ${ }^{4,5}$ and Zdeněk Joska ${ }^{6}$ \\ ${ }^{1}$ Department of Mathematical Analysis and Applications of Mathematics, Faculty of Science, Palacký University in Olomouc, \\ 17 Listopadu 12, 77146 Olomouc, Czech Republic \\ ${ }^{2}$ Institute of Measurement Science, Slovak Academy of Sciences, Dúbravská cesta 9, 84104 Bratislava, Slovakia \\ ${ }^{3}$ Department of Mathematics, Faculty of Applied Informatics, Tomas Bata University in Zlín, Nám. T.G. Masaryka 5555, \\ 76005 Zlín, Czech Republic \\ ${ }^{4}$ Institute of Clinical and Experimental Dental Medicine, First Faculty of Medicine, \\ Charles University General Teaching Hospital, Prague, Czech Republic \\ ${ }^{5}$ Onedent, Př́kop 8, 60200 Brno, Czech Republic \\ ${ }^{6}$ Communication and Information Systems Agency, Czech Army, Tychonova 1, 16001 Prague, Czech Republic
}

Correspondence should be addressed to Martina Chvosteková; chvosta@gmail.com

Received 30 November 2015; Accepted 30 December 2015

Copyright (C) 2016 Eva Fišerová et al. This is an open access article distributed under the Creative Commons Attribution License, which permits unrestricted use, distribution, and reproduction in any medium, provided the original work is properly cited.

In the paper titled "Survival Analysis of Factors Influencing Cyclic Fatigue of Nickel-Titanium Endodontic Instruments" [1], there was missing the second affiliation of (Martina Chvosteková) and is corrected above and there was an error in "Acknowledgments," which should be corrected as follows.

\section{Acknowledgment}

The authors thankfully acknowledge the support given by the Operational Program Education for Competitiveness, European Social Fund (Projects CZ.1.07/2.3.00/20.0170 and CZ.1.07/2.3.00/30.0041 of the Ministry of Education, Youth and Sports of the Czech Republic) and the Scientific Grant Agency VEGA of the Ministry of Education of the Slovak Republic and the Slovak Academy of Sciences (Projects VEGA 2/0047/15 and VEGA 2/0011/16).

\section{References}

[1] E. Fišerová, M. Chvosteková, S. Bělašková, M. Bumbálek, and Z. Joska, "Survival analysis of factors influencing cyclic fatigue of nickel-titanium endodontic instruments," Advances in Materials Science and Engineering, vol. 2015, Article ID 189703, 6 pages, 2015. 

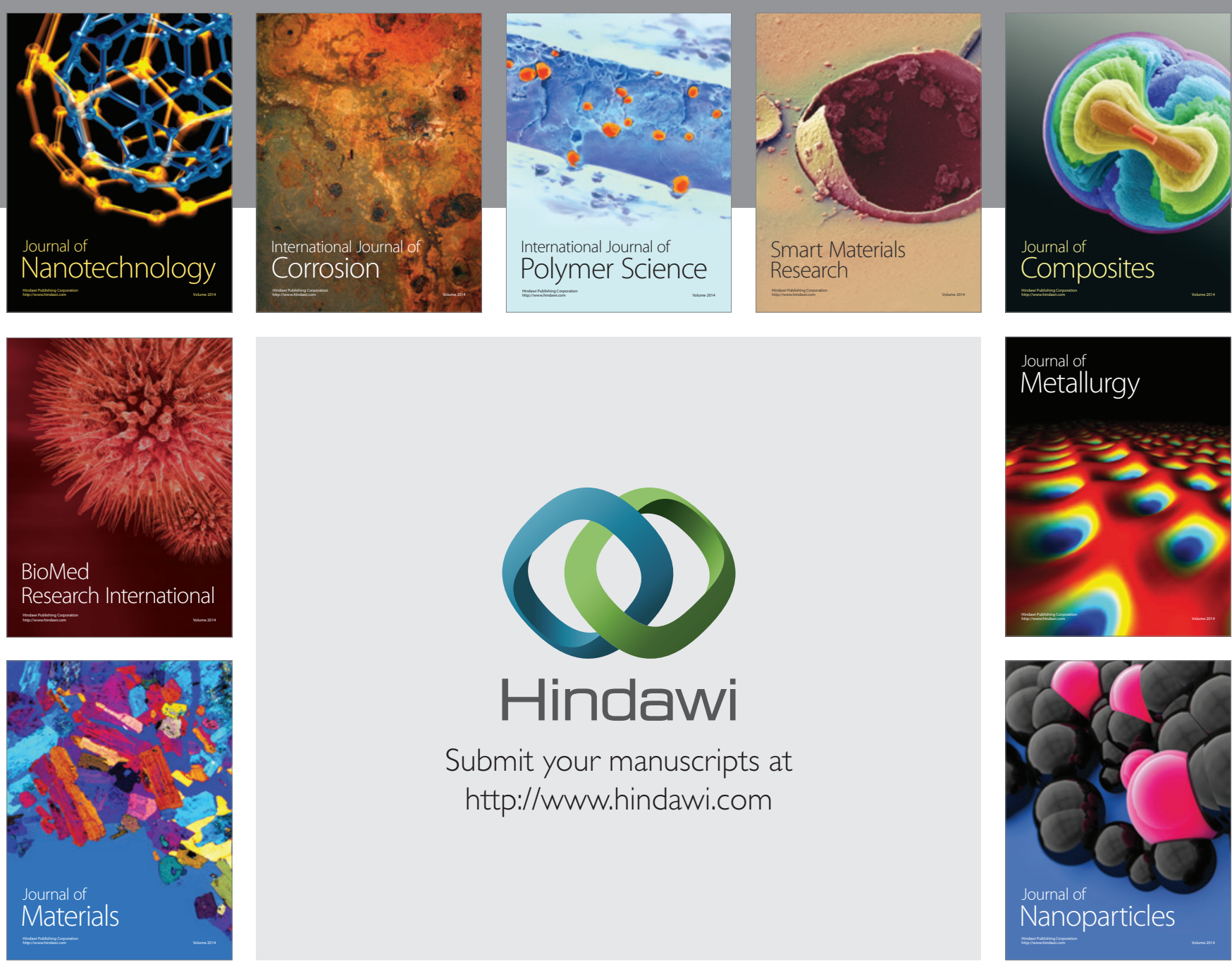

\section{Hindawi}

Submit your manuscripts at

http://www.hindawi.com

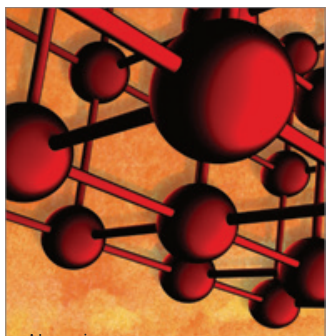

Materials Science and Engineering
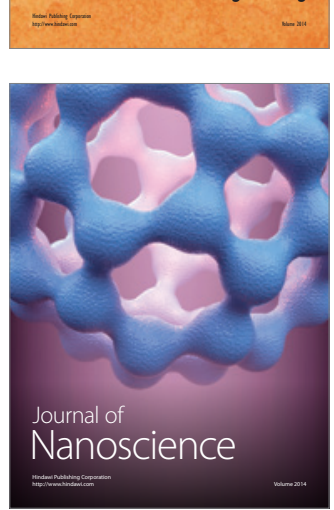
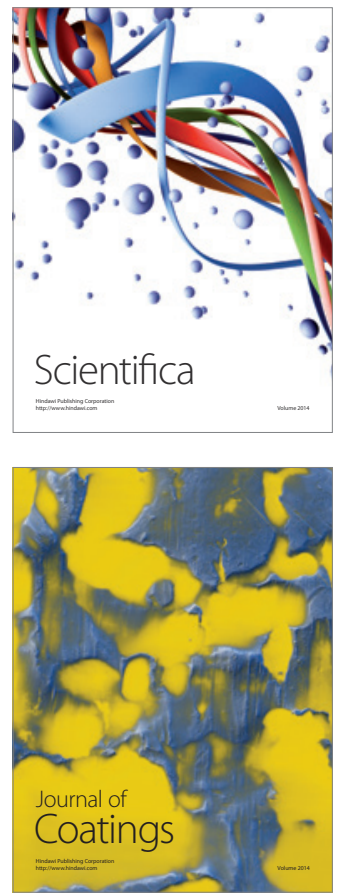
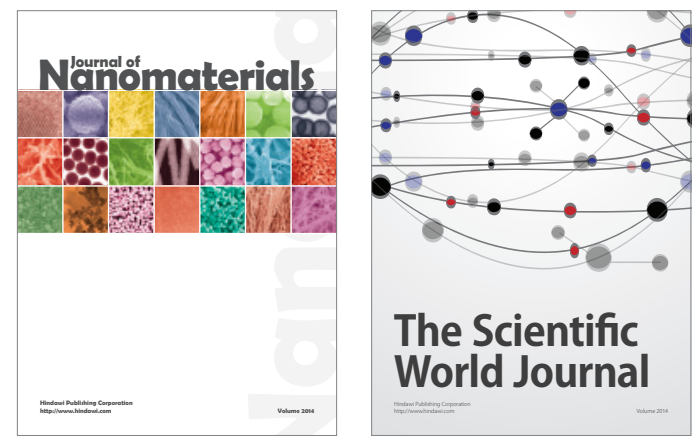

The Scientific World Journal
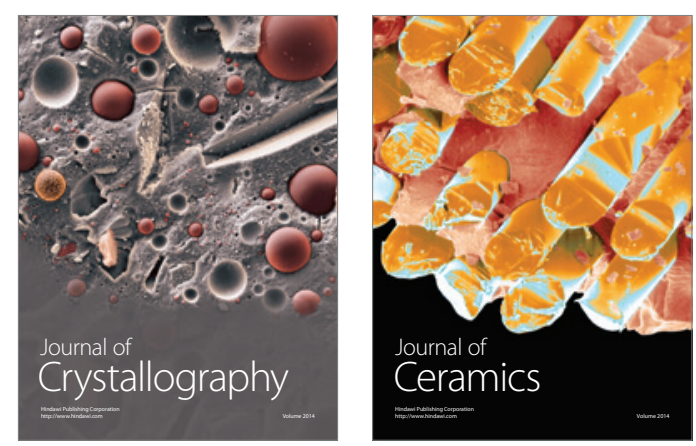
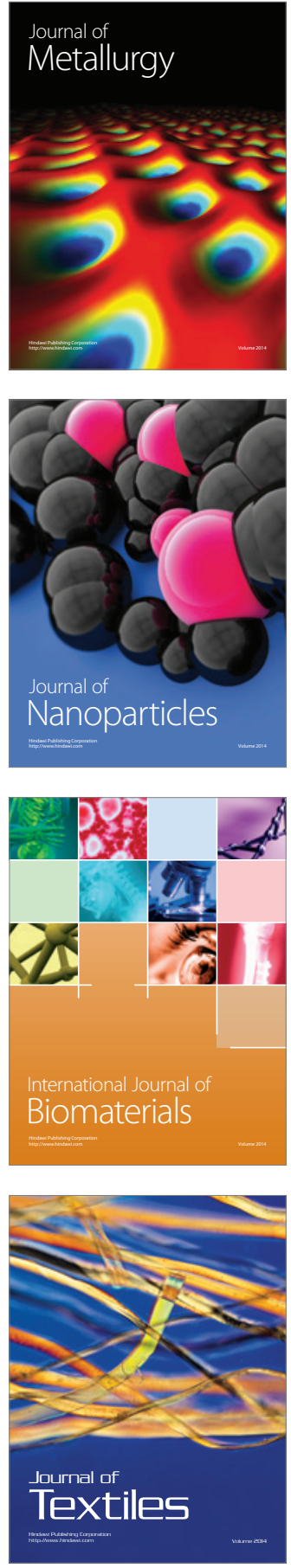